\title{
Salvianolic acid B attenuates lipopolysaccharide-induced acute lung injury in rats through inhibition of apoptosis, oxidative stress and inflammation
}

\author{
DA-HAI ZHAO ${ }^{1,2}$, YU-JIE WU ${ }^{1}$, SHU-TING LIU ${ }^{1}$ and RONG-YU LIU ${ }^{2}$ \\ ${ }^{1}$ Department of Respiratory Medicine, The Second Hospital of Anhui Medical University, Hefei, Anhui 230601; \\ ${ }^{2}$ Department of Pulmonary Medicine, Anhui Geriatric Institute, The First Hospital of Anhui Medical University, \\ Hefei, Anhui 230022, P.R. China
}

Received January 6, 2016; Accepted January 6, 2017

DOI: 10.3892/etm.2017.4534

\begin{abstract}
The present study was performed to assess the protective effect of salvianolic acid B on lipopolysaccharide (LPS)-induced acute lung injury (ALI). Sprague Dawley rats were injected with $100 \mu \mathrm{g} / \mathrm{kg}$ LPS through a 24 -gauge catheter. One group of rats was pre-treated with salvianolic acid $\mathrm{B}$ (1 $\mathrm{mg} / \mathrm{ml} ; 20 \mathrm{ml} / \mathrm{kg}$ body weight) $1 \mathrm{~h}$ prior to LPS challenge, then $20 \mathrm{ml} / \mathrm{kg}$ salvianolic acid B every 2 days for 4 weeks thereafter. Salvianolic acid B attenuated LPS-induced increases in the lung wet/dry weight rate and lung tissue injury in ALI model rats. LPS-induced changes in the content of caspase-3, malondialdehyde, superoxide dismutase, catalase, glutathione peroxidase, tumor necrosis factor- $\alpha$ and interleukin-6 in ALI model rats were attenuated by treatment with salvianolic acid B. Furthermore, treatment with salvianolic acid $\mathrm{B}$ inhibited the protein expression of type I collagen I, endogenous transforming growth factor- $\beta 1$ production and $\alpha$-smooth muscle actin in ALI model rats. These findings indicated that salvianolic acid B attenuates LPS-induced ALI through inhibition of apoptosis, oxidative stress and inflammation in rats and therefore exertsa protective effect against ALI.
\end{abstract}

\section{Introduction}

Acute lung injury (ALI) is defined as pulmonary dysfunction caused by pathogenic factors. It may aggravate to develop into more severe acute respiratory distress syndrome (ARDS) (1). In the clinic, affected patients present with intractable hypoxemia and progressive respiratory distress. The major associatedpathologic changes are extensive injury

Correspondence to: Dr Rong-Yu Liu, Department of Pulmonary Medicine, Anhui Geriatric Institute, The First Hospital of Anhui Medical University, 218 Jixi Road, Hefei, Anhui 230022, P.R. China E-mail: yabuw60@163.com

Key words: salvianolic acid B, acute lung injury, apoptosis, oxidative stress, inflammation of pulmonary capillary endothelial cells and alveolar epithelial cells (2). Subsequently, pneumonedema develops and the membrane becomes transparent (3). Major pathophysiological changes associated with ALI and ARDS are a decrease in lung compliance, diffusion disturbance and the disproportionality of ventilation/perfusion. The pathogenesis of ALI is complex and has remained to be fully elucidated (4). When ALI occurs, inflammatory cells, including neutrophils and macrophages, adhere, accumulate and can be activated in the lung (5). Afterwards, inflammatory cells produce large amounts of active oxygen and oxidase through respiratory burstand degranulation. Consequently, the pulmonary vasculature and alveolar epithelial cells are seriously damaged (6).

Apoptosis, also known as programmed cell death, refers to an active type of death in which cells themselves terminate their lives under certain physiological or pathological conditions. It is an essential process for organisms to maintain a dynamic equilibrium, which affects lesions and recovery of lung tissues (7). Excessive apoptosis of alveolar epithelial cells and vascular endothelial cells may result in structural distortion and destruction of pulmonary tissues as well as fibroblast proliferation. The association between apoptosis and ALI remains a hot topic (8).

In recent years, molecular biological mechanisms have received continuous attention. The pathway associated with biological damage of the lung is the induction of a lung inflammatory reaction mediated by cells and inflammation mediators (9). Biological damage refers to an inflammatory injury in which inflammatory mediators, cytokines and inflammatory cells participate. Mechanical and biological damage are connected with each other (7). ALI causes biological damage, while biological damage may exacerbate mechanical damage (10).

As a traditional Chinese medicine, Salvia miltiorrhizae has been employed in Asian countries to cure and prevent various types of disease with high efficacy (11). In recent years, two active components with the highest phamaceutical value have been extracted, i.e., tanshinone IIA and salvianolic acid B (Fig. 1) (12). The latter has been reported to aid inneural functional recovery in rats with cerebral injury (12). Furthermore, it was shown to have neuroprotective effects in rats with 
focal cerebral ischemic reperfusion (13). It has been suggested that theneural functional recoveryeffect of salvianolic acid $B$ is dependent on its specific chemical structure, which are accountable for is neuroprotective effects $(12,14)$. The present study assessed whether salvianolic acid B exerts a protective effect on LPS-induced ALI.

\section{Materials and methods}

Animals, experimental groups and LPS-induced ALI model. Adult male Sprague-Dawley (SD) rats weighing 50 $2 \mathrm{~g}$ were obtained from the Animal Center of Anhui Medical University (Hefei, China), and were housed in a humidity-controlled environment $\left(22 \pm 2^{\circ} \mathrm{C} ; 55 \pm 5 \%\right.$ humidity) with a 12 -h light/dark cycle and allowed free access to water and standard rat chow. The rats were anesthetized with an intraperitoneal injection of $3 \%$ pentobarbital sodium $(30 \mathrm{mg} / \mathrm{kg}$ body weight; Sinopharm Chemical Reagent Co., Ltd., Shanghai, China). Subsequently, $0.01 \%$ LPS (100 $\mu \mathrm{g} / \mathrm{kg}$ body weight; Sigma-Aldrich; Merck KGaA, Darmstadt, Germany) was injected into the tail vein of SD rats through a 24-gauge catheter. All 26 adult male SD rats were randomly divided into 3 groups: The control group (sham, $\mathrm{n}=6$ ), LPS-induced ALI model group (model, $\mathrm{n}=10$ ), salvianolic acid B-treated group (treated, $n=10$ ). The rats from the salvianolic acid B-treated group were pretreated with salvianolic acid $B(1 \mathrm{mg} / \mathrm{ml} ; 20 \mathrm{ml} / \mathrm{kg}$ body weight $) 1 \mathrm{~h}$ prior to LPS challenge, then $20 \mathrm{ml} / \mathrm{kg}$ of salvianolic acid B every 2 days for 4 weeks thereafter.

Lung wet/dry weight ratio. The right edematous lung tissue from every group was weighed to determine the tissue's wet weight. Subsequently, theright lung edema tissue was placed in an oven at $80^{\circ} \mathrm{C}$ for $24 \mathrm{~h}$ and weighed to determine the tissue dry weight. The tissue wet/dry weight ratio was then calculated.

Lung histopathology. The left edematous lung tissue from every group was fixed in $4 \%$ paraformaldehyde for $24 \mathrm{~h}$ and dehydrated by an ethanol gradient. The tissue was embedded in paraffin and sectioned into $4-\mu \mathrm{m}$ slices. Sliced tissue samples were stained with hematoxylin and eosin.

Determination of oxidative stress and inflammation. Lung homogenate $10 \%(\mathrm{w} / \mathrm{v})$ was prepared and centrifuged at $12,000 \mathrm{x} \mathrm{g}$ for $10 \mathrm{~min}$. The supernatant was collected and standard enzyme-linked immunosorbent assay kits were used to measure the content of caspase-3 (DYC835-2; R\&D Systems, Inc., Minneapolis, MN, USA), and malondialdehyde (MDA; A003-1), superoxide dismutase (SOD; A001-1), catalase (CAT; A007-1), glutathione peroxidase (GPx; A005; all from Nanjing Jiancheng Bioengineering Institute, Nanjing, China), tumor necrosis factor (TNF)- $\alpha$ (ab46070) and interleukin (IL)-6 (ab100772; both from Abcam, Cambridge, UK), according to the manufacturer's instructions.

Western blot analysis. Lung homogenate $10 \%$ (w/vol) was prepared and centrifuged at 12,000 x g for $10 \mathrm{~min}$. The supernatant was collected and used to measure protein contents using a bicinchoninic acid assay (Beyotime Institute of Biotechnology, Haimen, China). In brief, total protein (50 $\mu \mathrm{g} /$ lane) was subjected to $10-12 \%$ SDS-PAGE and subsequently transferred onto polyvinylidene difluoride membranes (EMD Millipore, Billerica, MA, USA). The membranes were then blocked with $5 \%$ skimmed milk in Tris-buffered saline with $0.1 \%$ Tween-20 (pH 7.4) and incubated with anti-transforming growth factor (TGF)- $\beta 1$ (1:2,000 dilution; 3709; Cell Signaling Technology, Inc., Danvers, MA, USA), anti- $\alpha$-smooth muscle actin (SMA; 1:2,000 dilution; ab5694; Abcam) anti-collagen I (1:2,000 dilution; ab34710; Abcam) or $\beta$-actin (1:5,000 dilution; sc-7210; Santa Cruz Biotechnology, Inc., Dallas, TX, USA) overnight at $4^{\circ} \mathrm{C}$. The membrane was incubated with horseradish peroxidase-conjugated secondary antibody (sc-2357, 1:2,000; Santa Cruz Biotechnology, Inc., Dallas, TX, USA) at $37^{\circ} \mathrm{C}$ for $2 \mathrm{~h}$.

Statistical analysis. Values are expressed as the mean \pm standard deviation by SPSS 17.0 software (SPSS, Inc., Chicago, IL, USA). One-way analysis of variance and pairwise comparison were performed. $\mathrm{P}<0.05$ was considered to indicate a statistically significant difference between values.

\section{Results}

Salvianolic acid B attenuates LPS-induced increases in the lung wet/dry weight ratio in rats. As shown in Fig. 2, the lung wet/dry weight ratio in the model group was higher than that in the sham group. The LPS-induced increase in the lung wet/dry weight ratio was markedly attenuated by salvianolic acid B pre-treatment in LPS-induced ALI rats (Fig. 2).

Salvianolic acid B attenuates LPS-induced lung tissue injury in rats. As shown in Fig. 3, sham rats had a normal lung morphology, while LPS-induced ALI rats exhibited extensive lung damage. Of note, pre-treatment with salvianolic acid B significantly attenuated LPS-induced lung tissue injury in rats (Fig. 3).

Salvianolic acid B attenuates LPS-induced increases in the content of caspase-3 in rats. As shown in Fig. 4, the lung tissue of LPS-induced ALI rats showed a significant increase in caspase-3 content compared with that in the sham group. However, treatment with salvianolic acid B significantly attenuated LPS-induced increases in the content of caspase-3 in the rat lungs (Fig. 4).

Salvianolic acid B attenuates LPS-induced oxidative stress in rats. When compared to that in the sham-operated rats, the MDA content was enhanced and the SOD, CAT and GPx content was attenuated in LPS-induced ALI rats (Fig. 5). Of note, salvianolic acid B treatment significantly attenuated these LPS-induced changes associated with oxidative stress in rats (Fig. 5).

Salvianolic acid B attenuates LPS-induced inflammation in rats. After LPS exposure, the levels of the TNF- $\alpha$ and IL-6 content in the rat lungs were significantly elevated compared to those in sham-operated animals (Fig. 6). Salvianolic acid B treatment significantly attenuated LPS-induced increases in the TNF- $\alpha$ and IL-6 content in rat lungs (Fig. 6).

Salvianolic acid B attenuates LPS-induced Col-I in rats. As shown in Fig. 6, the protein expression of Col-I in the rat lungs 
<smiles>O=C(/C=C/c1ccc(O)c2c1[C@@H](C(=O)O[C@H](Cc1ccc(O)c(O)c1)C(=O)O)[C@H](c1ccc(O)c(O)c1)O2)O[C@@H](Cc1ccc(O)c(O)c1)C(=O)O</smiles>

Figure 1. Chemical structure of salvianolic acid B.

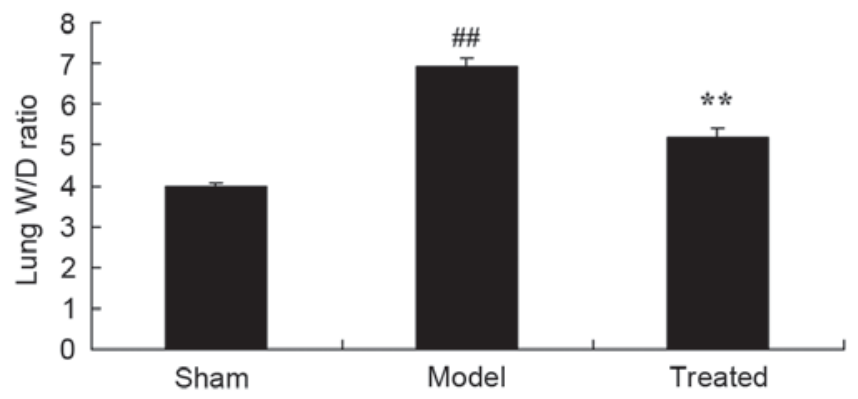

Figure 2. Salvianolic acid B attenuates LPS-induced increases in the lung W/D weight rate in rats. Groups: Sham, control group; model, LPS-induced acute lung injury model group; treated, salvianolic acid B-treated group ( $1 \mathrm{mg} / \mathrm{ml} ; 20 \mathrm{ml} / \mathrm{kg}$ body weight). ${ }^{\# \prime} \mathrm{P}<0.01$ vs. sham group, ${ }^{* * *} \mathrm{P}<0.01 \mathrm{vs.} \mathrm{model}$ group. W/D, wet/dry; LPS, lipopolysaccharide.

after LPS exposure was significantly higher than that in the sham rats (Fig. 7). The LPS-induced Col-I protein expression in the rat lungs was significantly attenuated by treatment with salvianolic acid B (Fig. 7).

Salvianolic acid B attenuates LPS-induced TGF- $\beta 1$ in rats. As shown in Fig. 8, TGF- $\beta 1$ protein expression ws siganificantly activated in rats after LPS exposure compared with that in sham rats. Treatment with salvianolic acid B significantly attenuated LPS-induced TGF- $\beta 1$ protein expression in ALI rats (Fig. 8).

Salvianolic acid $B$ attenuates LPS-induced $\alpha$-SMA in rats. When compared to that in the sham control rats, $\alpha$-SMA protein expression was observed to be increased in LPS-induced ALI rats (Fig. 9). Of note, salvianolic acid B treatment significantly attenuated LPS-induced $\alpha$-SMA protein expression in rats (Fig. 9).

\section{Discussion}

ALI is a syndrome of pulmonary inflammation and permeability characterized by gas exchange dysfunction (15). If it aggravates, it is referred to as ARDS in the clinic. Its pathological features are pulmonary capillary endothelial cell damage, alveolar epithelial cell injury, extensive aqualung, tiny pulmonary atelectasis, microthrombi and microcirculation disturbance (16). Common incentives include severe infection, trauma, shock and intoxication, such as inhalation of toxic gases. While the morbidity and fatality rates of affected patients are high, the advance of clinical methods and comprehensive treatments have decreased its mortality rate, which, however, remains as high as $30-40 \%$ (3). The mortality rates is also increased in
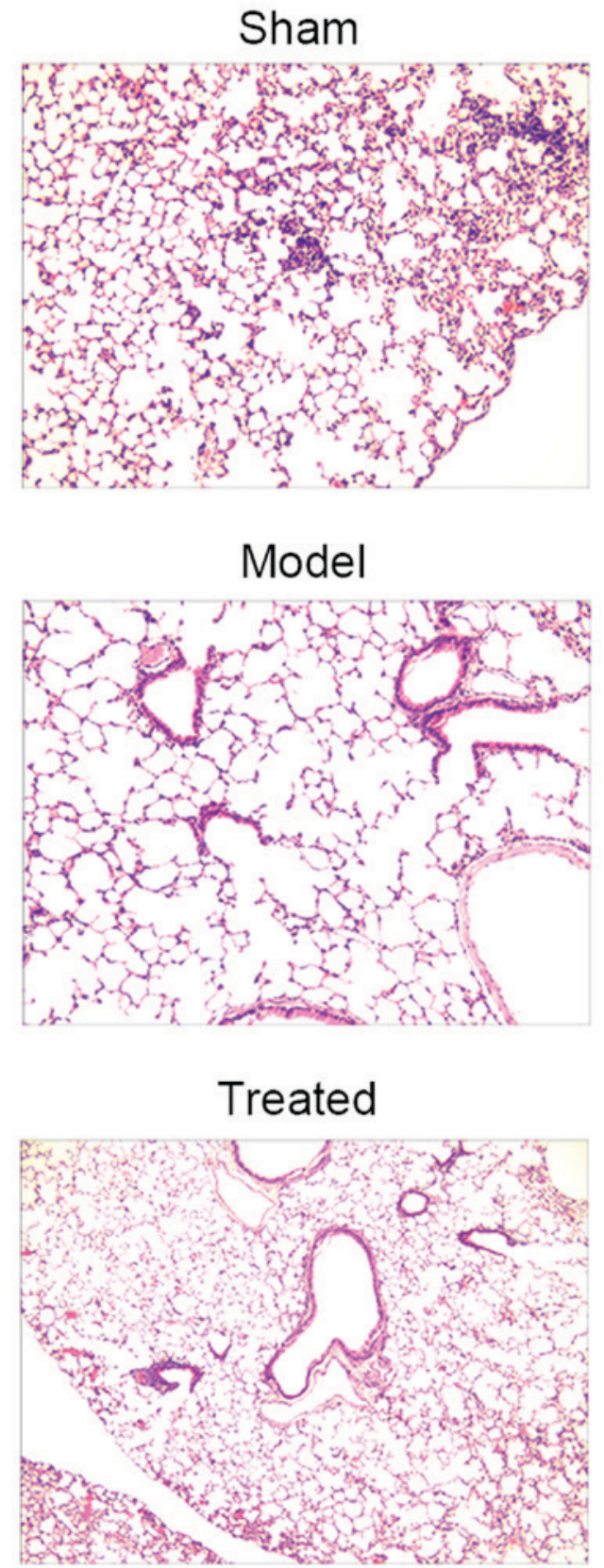

Figure 3. Salvianolic acid B attenuates LPS-induced lung tissue injury in rats. Representative histological images stained with hematoxylin and eosin are shown (magnification, x20). Groups: Sham, control group; model, LPS-induced acute lung injury model group; treated, salvianolic acid B-treated group (1 mg/ml; $20 \mathrm{ml} / \mathrm{kg}$ body weight). LPS, lipopolysaccharide.

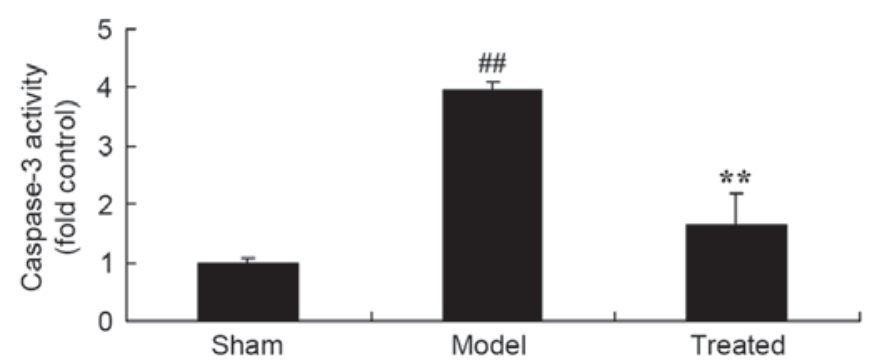

Figure 4. Salvianolic acid B attenuates LPS-induced increases of caspase-3 in in the lung tissues of rats. Groups: Sham, control group; model, LPS-induced acute lung injury model group; treated, salvianolic acid B-treated group ( $1 \mathrm{mg} / \mathrm{ml} ; 20 \mathrm{ml} / \mathrm{kg}$ body weight). ${ }^{\# \#} \mathrm{P}<0.01$ vs. sham group, ${ }^{* *} \mathrm{P}<0.01 \mathrm{vs}$. model group. LPS, lipopolysaccharide. 

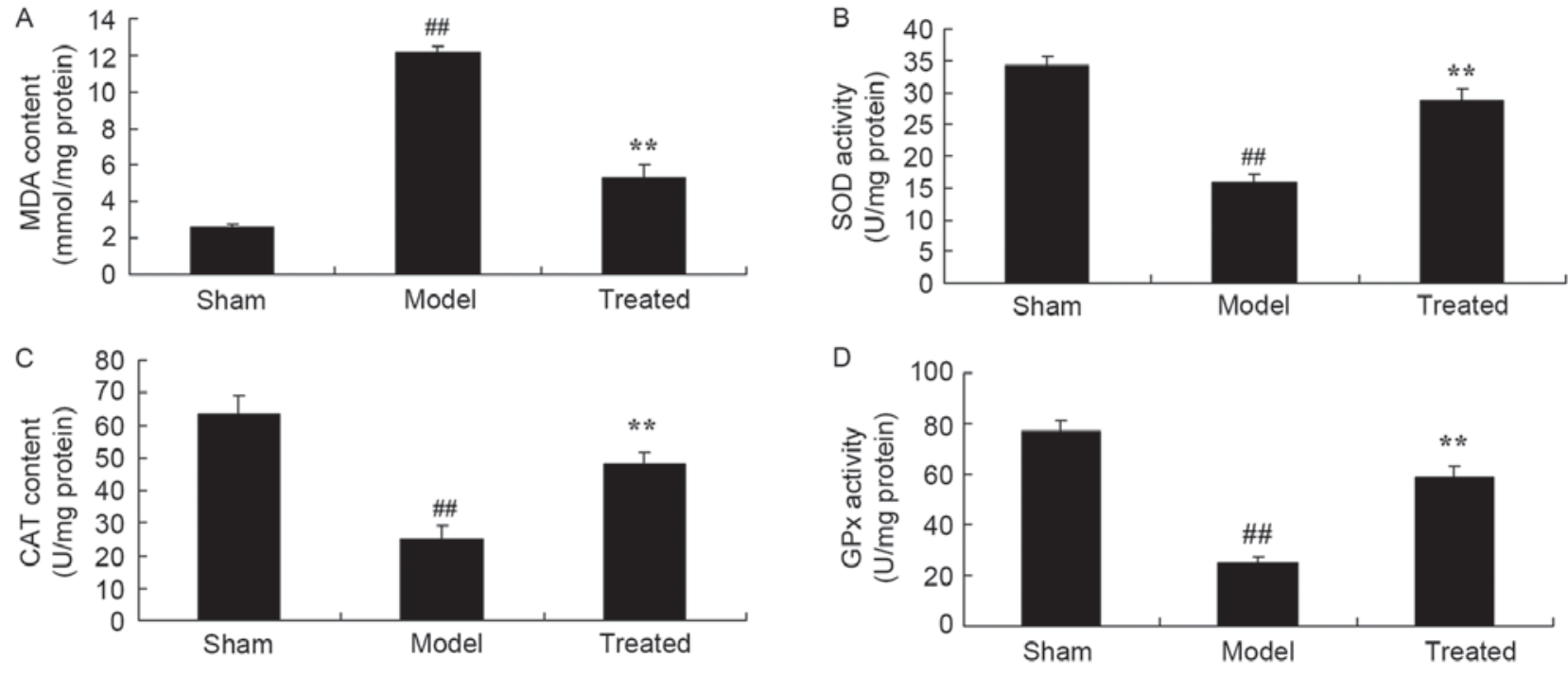

Figure 5. Salvianolic acid B attenuates LPS-induced oxidative stress inin the lung tissues of rats. Treatment with salvianolic acid B inhibited LPS-induced (A) increases in MDA as well as decreases in the (B) SOD, (C) CAT and (D) GPx content in rats. Groups: Sham, control group; model, LPS-induced acute lung injury model group; treated, salvianolic acid B-treated group $\left(1 \mathrm{mg} / \mathrm{ml} ; 20 \mathrm{ml} / \mathrm{kg}\right.$ body weight). ${ }^{\# \#} \mathrm{P}<0.01 \mathrm{vs}$. sham group, ${ }^{* *} \mathrm{P}<0.01 \mathrm{vs}$. model group. MDA, malondialdehyde; SOD, superoxide dismutase; CAT, catalase; GPx, glutathione peroxidase; LPS, lipopolysaccharide.
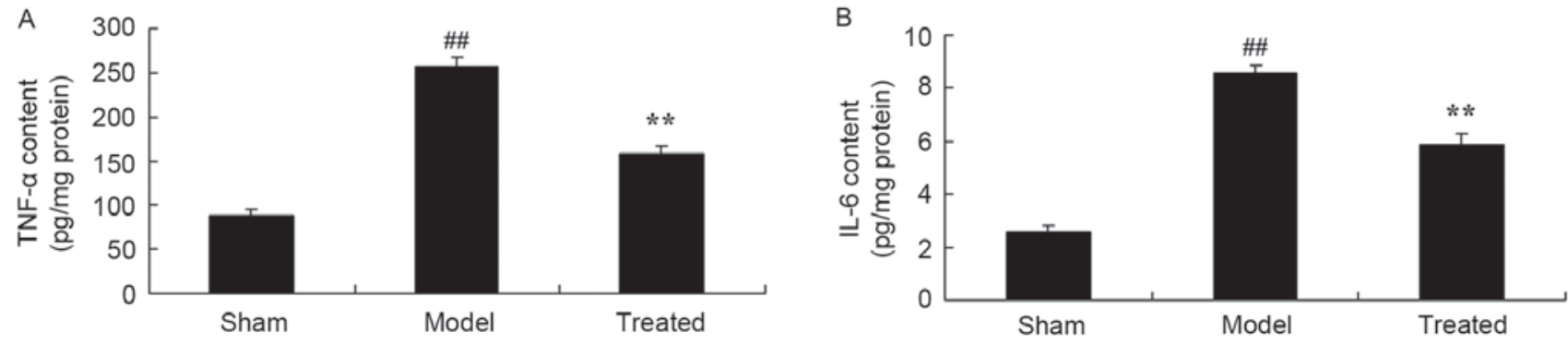

Figure 6. Salvianolic acid B attenuates LPS-induced inflammation in the lung tissues of rats. Treatment with salvianolic acid B attenuated LPS-induced increases in (A) TNF- $\alpha$ and (B) IL-6 contents in rats. Groups: Sham, control group; model, LPS-induced acute lung injury model group; treated, salvianolic acid B-treated group $\left(1 \mathrm{mg} / \mathrm{ml} ; 20 \mathrm{ml} / \mathrm{kg}\right.$ body weight). ${ }^{\# /} \mathrm{P}<0.01$ vs. sham group, ${ }^{* *} \mathrm{P}<0.01$ vs. model group. TNF, tumor necrosis factor; IL, interleukin; LPS, lipopolysaccharide.

patients with accompanying multiple organ dysfunction, with the mortality rate being $100 \%$ if more than four organ dysfunctions are present (17). In the present study, salvianolic acid B was shown to markedly attenuate the LPS-induced increase in the lung wet/dry weight ratio as well as lung tissue injury in ALI rats. Chen et al (12) reported that salvianolic acid B attenuates traumatic brain injury through exerting an anti-inflammatory effect in mice.

The pathogenesis of ALI is rather complex and it has remained to be fully clarified. However, oxidative stress is considered to be one of major pathogenic factors of ALI (18). Internally (hypoxia-ischemia or inflammation) and externally (pressure, empyrosis), organisms produce large amounts of reactive oxygen, which destroys the equilibrium state of the oxidation/antioxidant system (19). Cell or tissue damage may occur to cause associated diseases, such as tumors or diabetes (20). This process is referred to as oxidative stress. The results of the present study indicated that salvianolic acid B exerts protective effects against LPS-induced oxidative stress in ALI rats. Yang et al (14) suggested that salvianolic acid B protects against low-density lipoprotein oxidation and neointimal hyperplasia through inhibition of reactive oxygen species production in endothelium-denuded hypercholesterolaemic rabbits.

The current understanding of apoptotic processes has shifted from cell nucleus-centered to mitochondria-centered mechanisms (8). It is thought that mitochondria have a decisive role in apoptotic processes. As an endogenous apoptotic pathway, the mitochondrial apoptotic pathway is regarded as the key regulatory process (21). The primary functions of mitochondria in cell apoptosis include the release of activity factors of caspase, such as cytochrome $c$, the loss of the mitochondrial transmembrane potential and dysfunction of oxidative phosphorylation of mitochondria (22). During this process, cytochrome $c$ and caspase- 3 have an essential role. Consistent with this, the results of the present study demonstrated that treatment with salvianolic acid B significantly attenuated LPS-induced increases in the content of caspase- 3 in the lungs of ALI rats. Tang et al (23) suggested that salvianolic acid B protects human endothelial progenitor cells through inhibiting oxidative stress and caspase-3 activation.

Cells as well as body fluids participate in the inflammatory response (24). Cells participating in inflammation include polymorphonuclear neutrophil (PMN), alveolar epithelial 
A

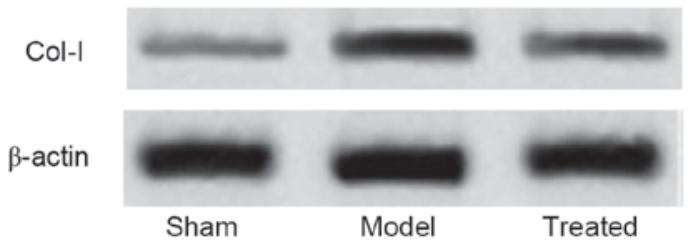

B

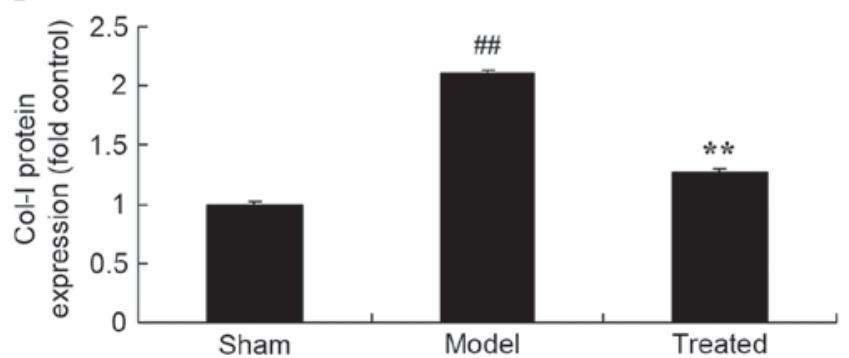

Figure 7. Salvianolic acid B attenuates LPS-induced Col-I in in the lung tissues of rats. (A) Western blots showing that treatment with salvianolic acid B attenuated LPS-induced Col-I protein. (B) Quantified protein expression levels of Col-I in rats. Groups: Sham, control group; model, LPS-induced acute lung injury model group; treated, salvianolic acid B-treated group ( $1 \mathrm{mg} / \mathrm{ml} ; 20 \mathrm{ml} / \mathrm{kg}$ body weight). ${ }^{\# \#} \mathrm{P}<0.01$ vs. sham group, ${ }^{* *} \mathrm{P}<0.01 \mathrm{vs}$. model group. Col-I, collagen I; LPS, lipopolysaccharide.

A

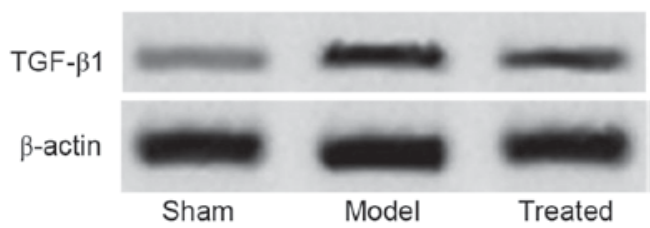

B

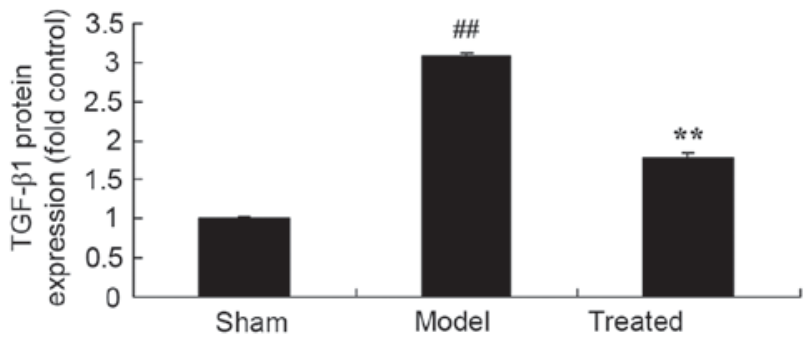

Figure 8. Salvianolic acid B attenuates LPS-induced TGF- $\beta 1$ in the lung tissues of rats. (A) Western blot showing that treatment with salvianolic acid B reduced LPS-induced increases in TGF- $\beta 1$ in rats. (B) Quantified protein expression levels of TGF- $\beta 1$. Groups: Sham, control group; model, LPS-induced acute lung injury model group; treated, salvianolic acid B-treated group ( $1 \mathrm{mg} / \mathrm{ml} ; 20 \mathrm{ml} / \mathrm{kg}$ body weight). ${ }^{\#} \mathrm{P}<0.01 \mathrm{vs}$. sham group, ${ }^{* *} \mathrm{P}<0.01$ vs. model group. TGF, transforming growth factor; LPS lipopolysaccharide.

cells, vascular endothelial cells, pulmonary vascular endothelial cells, alveolar macrophages, pulmonary interstitial macrophages and pulmonary intravascular macrophages, among which PMN and pulmonary intravascular macrophageshave a pivotal role in lung injury (25). Bodily fluids include cytokines, lipid mediators, oxygen radicals, proteases, alexin, cruor and the fibrinolytic system (7). Consistent with this, the present study found thats alvianolic acid B treatment significantly attenuated LPS-induced increases in the TNF- $\alpha$ and IL- 6 content in the lungs of ALI rats. Xu et al (11) suggested that salvianolic acid B attenuates platelet-mediated inflammatory responses in vascular endothelial cells.
A

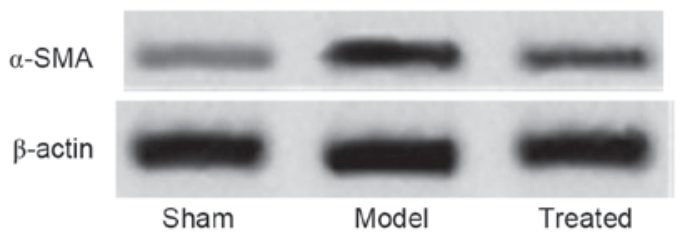

B

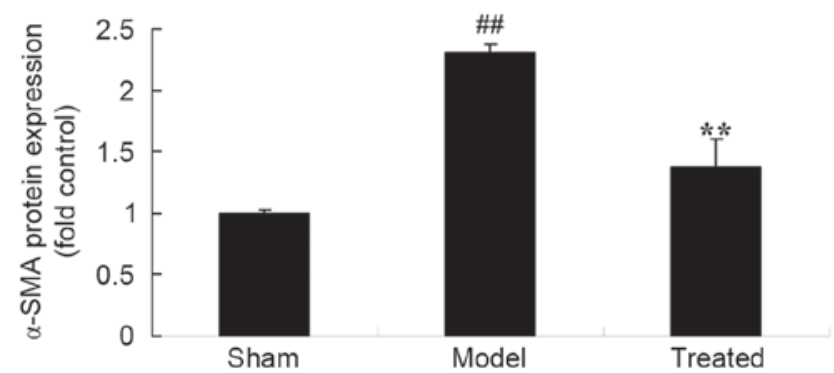

Figure 9. Salvianolic acid B attenuates LPS-induced $\alpha$-SMA in the lung tissues of rats. (A) Western blot showing that treatment with salvianolic acid $B$ reduced LPS-induced increases in $\alpha$-SMA protein. (B) Quantified protein expression levels of $\alpha$-SMA. Groups: Sham, control group; model, LPS-induced acute lung injury model group; treated, salvianolic acid B-treated group $(1 \mathrm{mg} / \mathrm{ml}$; $20 \mathrm{ml} / \mathrm{kg}$ body weight). ${ }^{\# \#} \mathrm{P}<0.01$ vs. sham group, ${ }^{* *} \mathrm{P}<0.01$ vs. model group. SMA, smooth muscle actin; LPS, lipopolysaccharide.

Cytokines in the lung can be expressed in intrinsic pulmonary cells, such as epithelial cells, vascular endothelial cells and interstitial cells. Furthermore, they may be secreted by inflammatory cells activated during lung injury processes, including macrophages and lymphocytes, which may have biological effects in the lung (26). In cytokines participating in radiation-induced lung injury, TGF- $\beta$ has a predominant role and is a major cytokine, which has been most thoroughly researched. It may induce inflammatory cells and fibroblasts to synthesize IL-1 and IL-6 (27). Furthermore, it may self-induce the production of more TGF- $\beta$ and inhibit the degradation of extracellular matrix (ECM). It induces fibroblasts to interact with compound ECM and promotes the adhesion between ECM and cells. It stimulates fibroblasts to proliferate and induces the expression of collagen RNAI and III. The fastigium of TGF- $\beta$ expression corresponds to the vigorous stage of fibroblast proliferation and collagen synthesis, suggesting that TGF- $\beta$ and other cytokines mediate the early inflammatory response (27). $\alpha$-SMA, which is the primary molecule of ALI, mainly exists in the cytoplasm. Studies found that TGF- $\beta 1$ induces the transformation of fibroblasts and pulmonary epithelial cells to generate ALI, which increases the expression of $\alpha$-SMA (28). The present study found that salvianolic acid $B$ attenuated LPS-induced increases in Col-I, TGF- $\beta 1$ and $\alpha$-SMA protein expression in the lung tissues of ALI rats. Li et al (29) indicated that salvianolic acid $\mathrm{B}$ attenuated hepatic fibrosis through Col-I, $\alpha$-SMA and TGF- $\beta$ signaling in rats. $\mathrm{Lv}$ and $\mathrm{Xu}(30)$ reported that salvianolic acid $\mathrm{B}$ inhibits TGF- $\beta 1$ in the stimulated human hepatic stellate cell line LX-2.

In conclusion, the results of the present study indicated that salvianolic acid B markedly attenuated LPS-induced increases in the lung wet/dry weight ratio as well as lung tissue injury in ALI model rats via inhibition of apoptosis, oxidative stress and inflammation. These findings suggested that the clinical applicability of salvianolic acid B in the prevention and treatment of ALI warrants further exploration. 


\section{References}

1. Krupa A, Fol M, Rahman M, Stokes KY, Florence JM, Leskov IL, Khoretonenko MV, Matthay MA, Liu KD, Calfee CS, et al: Silencing Bruton's tyrosine kinase in alveolar neutrophils protects mice from LPS/immune complex-induced acute lung injury. Am J Physiol Lung Cell Mol Physiol 307: L435-L448, 2014.

2. Stapleton RD, Martin TR, Weiss NS, Crowley JJ, Gundel SJ, Nathens AB, Akhtar SR, Ruzinski JT, Caldwell E, Curtis JR, et al: A phase II randomized placebo-controlled trial of omega-3 fatty acids for the treatment of acute lung injury. Crit Care Med 39: 1655-1662, 2011.

3. Calfee CS, Gallagher D, Abbott J, Thompson BT and Matthay MA; NHLBI ARDS Network: Plasma angiopoietin-2 in clinical acute lung injury: Prognostic and pathogenetic significance. Crit Care Med 40: 1731-1737, 2012.

4. McAuley DF, Laffey JG, O'Kane CM, Cross M, Perkins GD, Murphy L, McNally C, Crealey G and Stevenson M; HARP-2 investigators; Irish Critical Care Trials Group: Hydroxymethylglutaryl-CoA reductase inhibition with simvastatin in acute lung injury to reduce pulmonary dysfunction (HARP-2) trial: Study protocol for a randomized controlled trial. Trials 13: 170, 2012.

5. Needham DM, Wozniak AW, Hough CL, Morris PE, Dinglas VD, Jackson JC, Mendez-Tellez PA, Shanholtz C, Ely EW, Colantuoni E, et al: Risk factors for physical impairment after acute lung injury in a national, multicenter study. Am J Respir Crit Care Med 189: 1214-1224, 2014.

6. Clark BJ, Williams A, Feemster LM, Bradley KA, Macht M, Moss $\mathrm{M}$ and Burnham EL; NHLBI ARDS Network Investigators: Alcohol screening scores and 90-day outcomes in patients with acute lung injury. Crit Care Med 41: 1518-1525, 2013.

7. Zhou L, Zhao D, An H, Zhang H, Jiang C and Yang B: Melatonin prevents lung injury induced by hepatic ischemia-reperfusion through anti-inflammatory and anti-apoptosis effects. Int Immunopharmacol 29: 462-467, 2015.

8. Armstrong SM, Wang C, Tigdi J, Si X, Dumpit C, Charles S, Gamage A, Moraes TJ and Lee WL: Influenza infects lung microvascular endothelium leading to microvascular leak: Role of apoptosis and claudin-5. PLoS One 7: e47323, 2012.

9. Kohira S, Oka N, Inoue N, Itatani K, Hanayama N, Kitamura T, Fujii M, Takeda A, Oshima H, Tojo K, et al: Effect of the neutrophil elastase inhibitor sivelestat on perioperative inflammatory response after pediatric heart surgery with cardiopulmonary bypass: A prospective randomized study. Artif Organs 37: 1027-1033, 2013

10. Lv H, Yu Z, Zheng Y, Wang L, Qin X, Cheng G and Ci X: Isovitexin exerts anti-inflammatory and anti-oxidant activities on lipopolysaccharide-induced acute lung injury by inhibiting MAPK and NF- $\kappa \mathrm{B}$ and activating $\mathrm{HO}-1 / \mathrm{Nrf} 2$ pathways. Int J Biol Sci 12: 72-86, 2016.

11. Xu S, Zhong A, Bu X, Ma H, Li W, Xu X and Zhang J: Salvianolic acid B inhibits platelets-mediated inflammatory response in vascular endothelial cells. Thromb Res 135: 137-145, 2015

12. Chen T, Liu W, Chao X, Zhang L, Qu Y, Huo J and Fei Z: Salvianolic acid $\mathrm{B}$ attenuates brain damage and inflammation after traumatic brain injury in mice. Brain Res Bull 84: 163-168, 2011.

13. Xue L, Wu Z, Ji XP, Gao XQ and Guo YH: Effect and mechanism of salvianolic acid $B$ on the myocardial ischemia-reperfusion injury in rats. Asian Pac J Trop Med 7: 280-284, 2014.

14. Yang TL, Lin FY, Chen YH, Chiu JJ, Shiao MS, Tsai CS, Lin SJ and Chen YL: Salvianolic acid B inhibits low-density lipoprotein oxidation and neointimal hyperplasia in endothelium-denuded hypercholesterolaemic rabbits. J Sci Food Agric 91: 134-141, 2011.

15. Walkey AJ and Wiener RS: Utilization patterns and patient outcomes associated with use of rescue therapies in acute lung injury. Crit Care Med 39: 1322-1328, 2011.
16. Kowalski S, McMullen MC, Girling LG and McCarthy BG: Biologically variable ventilation in patients with acute lung injury: A pilot study. Can J Anaesth 60: 502-503, 2013.

17. Martin GS, Moss M, Wheeler AP, Mealer M, Morris JA and Bernard GR: A randomized, controlled trial of furosemide with or without albumin in hypoproteinemic patients with acute lung injury. Crit Care Med 33: 1681-1687, 2005.

18. Afshari A, Brok J, Moller AM and Wetterslev J: Inhaled nitric oxide for acute respiratory distress syndrome and acute lung injury in adults and children: A systematic review with meta-analysis and trial sequential analysis. Anesth Analg 112: 1411-1421, 2011.

19. Grainge C, Brown R, Jugg BJ, Smith AJ, Mann TM, Jenner J, Rice P and Parkhouse DA: Early treatment with nebulised salbutamol worsens physiological measures and does not improve survival following phosgene induced acute lung injury. J R Army Med Corps 155: 105-109, 2009.

20. Akcilar R, Akcilar A, Şimşek H, Koçak FE, Koçak C, Yümün G and Bayat Z: Hyperbaric oxygen treatment ameliorates lung injury in paraquat intoxicated rats. Int J Clin Exp Pathol 8: 13034-13042, 2015.

21. Ruchko MV, Gorodnya OM, Zuleta A, Pastukh VM and Gillespie MN: The DNA glycosylase Ogg1 defends against oxidant-induced mtDNA damage and apoptosis in pulmonary artery endothelial cells. Free Radic Biol Med 50: 1107-1113, 2011.

22. Ren M, Wang YM, Zhao J, Zhao J, Zhao ZM, Zhang TF, He J, Ren SP and Peng SQ: Metallothioneins attenuate paraquat-induced acute lung injury in mice through the mechanisms of anti-oxidation and anti-apoptosis. Food Chem Toxicol 73: 140-147, 2014.

23. Tang Y, Jacobi A, Vater C, Zou X and Stiehler M: Salvianolic acid B protects human endothelial progenitor cells against oxidative stress-mediated dysfunction by modulating Akt/mTOR/4EBP1, p38 MAPK/ATF2 and ERK1/2 signaling pathways. Biochem Pharmacol 90: 34-49, 2014

24. Chen WY, Huang YC, Yang ML, Lee CY, Chen CJ, Yeh CH, Pan PH, Horng CT, Kuo WH and Kuan YH: Protective effect of rutin on LPS-induced acute lung injury via down-regulation of MIP-2 expression and MMP-9 activation through inhibition of Akt phosphorylation. Int Immunopharmacol 22: 409-413, 2014.

25. Chen W, Ge X, Xu F, Zhang Y, Liu Z, Pan J, Song J, Dai Y, Zhou J, Feng J and Liang G: Design, synthesis and biological evaluation of paralleled Aza resveratrol-chalcone compounds as potential anti-inflammatory agents for the treatment of acute lung injury. Bioorg Med Chem Lett 25: 2998-3004, 2015.

26. Kim J, Jeong SW, Quan H, Jeong CW, Choi JI and Bae HB: Effect of curcumin (Curcuma longa extract) on LPS-induced acute lung injury is mediated by the activation of AMPK. J Anesth 30: 100-108, 2016.

27. Manickam N, Patel M, Griendling KK, Gorin Y and Barnes JL: RhoA/Rho kinase mediates TGF- $\beta 1$-induced kidney myofibroblast activation through Poldip2/Nox4-derived reactive oxygen species. Am J Physiol Renal Physiol 307: F159-F171, 2014.

28. Yang L, Hu J, Hao HZ, Yin Z, Liu G and Zou XJ: Sodium tanshinone IIA sulfonate attenuates the transforming growth factor- $\beta 1$-induced differentiation of atrial fibroblasts into myofibroblasts in vitro. Int J Mol Med 35: 1026-1032, 2015.

29. Li S, Wang L, Yan X, Wang Q, Tao Y, Li J, Peng Y, Liu P and Liu C: Salvianolic acid B attenuates rat hepatic fibrosis via downregulating angiotensin II signaling. Evid Based Complement Alternat Med 2012: 160726, 2012.

30. Lv Z and Xu L: Salvianolic acid B inhibits ERK and p38 MAPK signaling in TGF- $\beta 1$-stimulated human hepatic stellate cell line (LX-2) via distinct pathways. Evid Based Complement Alternat Med 2012: 960128, 2012. 